$\left(\frac{d^{2}}{z^{2}} \kappa\right) \times K_{v} . \quad$ Hence, if we calculate the value of $\left(\frac{d^{2}}{w} \kappa\right)$ first, we may proceed without further change to use the general tables, or to calculate trajectories, using the tabular values of $\mathrm{K}_{i}$, just as, when no change is required in the value of the tabulated coefficients. For the 3-, 5-, 7-, and 9-inch guns, the value of $\kappa$, in the cases we have considered, would be $\mathrm{I} \cdot 08$, $0 \cdot 92, \mathbf{I} \cdot 05$, and $\mathbf{I} \cdot 08$ respectively. There was one case where the studs did not act, when $K_{950}$ was found to be $335^{\circ}$ instead of $75^{\circ} \mathrm{O}$, which gives $\kappa=4.47$. The smaller the value of $k$ the steadier will be the motion of the shot. Mr. Ristori might calculate another range, using $\kappa=0.92$ given by the 5inch gun, if he be satisfied that he has got the correct initial velocity and initial direction of the shot. If the calculated and measured ranges did not now quite agree, the remaining correction of $\kappa$ might be found perhaps with sufficient accuracy by proportional parts. This seems to be the best way of expressing the degree of steadiness of shot when they are so light as to have their motion disturbed by cutting the threads of screens. But for heavy shot the most direct way is to fire through equidistant screens as already explained.

When I made experiments with low velocities in 1879 , I was furnished with some range tables of the 6.3 -inch Howitzer, where, it was said, my coefficients did not give correct results. As the difficulty in obtaining good results increases as the velocity decreases, I took the trouble to make a thorough comparison between the calculated and experimental results in the above case. I also made use of some German range tables in the same way, where the value of $d^{2} \div w$ was only a trifle larger. The results of these comparisons may be found at pp. 45-49 of my Final Report, 1880, which appear to me quite satisfactory.

So long as there are guns good, bad, and indifferent, it is clear that no single set of coefficients can give ranges suited to all cases. But ranges, \&c., calculated by the help of my coefficients, may serve as a standard of comparison applicable to every case, and so give a measure of the steadiness of the shot.

$$
\text { April } 23
$$

Francis BashForth

\section{The Dry and Wet Bulb Thermometers "Froude"}

A SO-CALLED thermometer "froude" has been used in France for many years, and its use, on special occasions, has gradually extended to other countries. It consists of an ordinary thermometer fastencd to a string two to four feet in length. If such a thermometer be swung through a circle whose radius is the length of the string, it is evident that it will attain the temperature of a large mass of air unless the results are vitiated by friction with the air, oxidation, centrifugal action, or other causes. Careful comparisons, at high and low velocities, with a thermometer properly exposed, have given entirely reliable results.

Some time ago the writer attempted to use this instrument as a wet bulb with such results that it was dccided to fasten two thermometers together, one with its bulb one and a half inches below the other. The latter may be easily wet by immersion without wetting the dry. This arrangement has worked admirably, and has been in constant use the past winter in determining temperature and humidity conditions both in city and country, in courts and rooms. Every one who has undertaken humidity observations with a wet bulb thermometer, especially in cold calm weather, has found it very difficult to obtain good results even after an hour's waiting after wetting. With this instrument it is an easy matter in every instance to obtain an absolutely correct result in two or three minutes. This is shown by the fact that repeated wetting and swinging will give the same result as often as tried. If ice is on the bulb, it is best, after swinging for several observations, or until the clear glare of ice has gone, to wet in water above freezing so as to remove the old ice and form a new coat. Distilled water should also be used if possible.

With this instrument it has been found that, in order to get even approximate results of humidity above grass ground, in clear calm weather, with temperature below freezing, the observation must be made upon a knoll, never in a valley or upon a plain with rising ground on any side. It has also been found that under the above conditions in the morning a height of twenty to thirty feet is essential, even upon a knoll, in order to obviate the effect of the gradual accumulation through the night of damp air above sod.

H. A. Hazen

April r 4

\section{Extraordinary Darkness at Midday}

THE extraordinary darkness that occurred here suddenly on the morning of the 26th is deserving of record, as being the most intense that is remembered by any of the inhabitants.

The early morning was bright, and no change was noticed until close upon is a.m., when the sky became rapidly darker in the west-south-west. The wind was blowing from the northcast at II a.m. with a velocity of five miles an hour, and it scarcely changed at II.40, when it increased to seven miles an hour, and veered at once to south-west, and then moved more slowly round through west and north, back again to east at $\mathbf{x}$ p.m., when its velocity was only three miles an hour.

At II. 30 the darkness was so great that it was found impossible to read even bold print (small pica) close by the window, and at this time a dense black cloud with a slightly yellowish tinge hung over the south-west sky; the blackness being most intense at $10^{\circ}$ above the horizon. At II. 35 it became somewhat lighter, and at $\mathrm{I}$.40 the rain began to fall, and in forty minutes O.rI4 inch of rain-water was collected in our rain-gauges, the whole being almost as black as ink, and full of fine carbon in suspension. Hail that fell a mile off to the south-west by south, and both hail and snow that fell on the hills two miles to the west, were also black. At Preston, fourteen miles to the southwest, the darkness was very marked, but five and a half miles to the north-east nothing very particular was noted.

Stonyhurst Observatory, April 28

S. J. PERry

\section{Intelligence in Animals}

I THINk it was about the year 1844 that the Duke of Argyll desired my late father, his factor, to preserve game in the district of Kintyre, Argyllshire. If any steps in this direction had been taken by other proprietors, they were very irregular. My memory goes back to about 1846 and 1848 , and at that time the grouse of Kintyre "sat like stones"--they might be shot to dogs from the first to the last day of the season; in fact it was often difficult to get the birds up. With this preservation, grouse increased enormously--and therefore the food supply of the people - to such an extent that the late Sir John Cuningham and my father shot, on one I 2 th of August, seventy-two brace of grouse. Sir John was a very old man, and insisted on loading his own gun, an old muzzle-loader. My father never shot hard. Now I do not believe any two men with two guns and loaders could do this in the same district with all the improvements in arms and dogs; whilst I have heard my father say that seven brace was a good bag when he was young, before game-preserving.

Grouse yet sit pretty well in Kintyre, and I believe this is the case because it was one of the last districts to preserve and shoot; but the birds are every year becoming wilder, and now in the month of September it is useless to take dogs on the hill, and for two years we, like others, have had to drive them.

$I$ account for this by an alteration in instinct, and I am as sure as any one can be, from observation and the opinion of competent persons, that it is progressive instinct in successive generations. Formerly the great enemies of the grouse were ravens, that took their eggs and young birds; foxes, polecats or martin cats, and wild cats, that took them at night on the ground ; and hawks, that took them on the wing during the day. When man stepped in and altered the balance of Nature, the

$$
\begin{aligned}
& \text { Bird that up and flew away, } \\
& \text { He lived to breed another day. }
\end{aligned}
$$

No hawk was there to knock him down. He found from experience that flying away before man and his dog came near gave him safety; and his children that inherited the wit or instinct or power of turning heather into nerve-force or intelligent thought-or whatever the straw-splitters like to call it--lived; whilst his brother, that inherited the qualities which kept him hiding in the heather, was shot when forced up.

I had this summer ample corroboration of this theory. About eight years ago I was shooting in the island of Rum; the grouse were not preserved and were extremely tame, so tame in September and October that I had to run after them to make them take the wing, and it was new to dogs. Last year I again shot in the island, and I observed the same tameness in one part of the island, but in another district I observed the grouse were larger, darker, and much wilder. I was puzzled with this until I found out that the late tenant had three years before turned down some English grouse, and in the district where they were so turned down the grouse were very wild.

Knockrioch, April 28
DUNCAN STEWART 